\title{
Ethylene Signaling Renders the Jasmonate Response of Arabidopsis Insensitive to Future Suppression by Salicylic Acid
}

\author{
Antonio Leon-Reyes, ${ }^{1}$ Yujuan Du, ${ }^{1}$ Annemart Koornneef, ${ }^{1}$ Silvia Proietti, ${ }^{1,3}$ Ana P. Körbes, ${ }^{2}$ \\ Johan Memelink, ${ }^{2}$ Corné M. J. Pieterse, ${ }^{1,4}$ and Tita Ritsema ${ }^{1}$ \\ ${ }^{1}$ Plant-Microbe Interactions, Department of Biology, Faculty of Science, Utrecht University, P.O. Box 800.56, 3508 TB \\ Utrecht, The Netherlands; ${ }^{2}$ Institute of Biology, Leiden University, P.O. Box 9505, 2300 RA Leiden, The Netherlands; \\ ${ }^{3}$ Dipartimento di Agrobiologia e Agrochimica, Universita' della Tuscia, Viterbo, 01100, Italy; ${ }^{4}$ Centre for BioSystems Genomics, \\ P.O. Box 98,6700 AB Wageningen, The Netherlands
}

Submitted 11 September 2009. Accepted 12 October 2009.

Cross-talk between jasmonate (JA), ethylene (ET), and Salicylic acid (SA) signaling is thought to operate as a mechanism to fine-tune induced defenses that are activated in response to multiple attackers. Here, 43 Arabidopsis genotypes impaired in hormone signaling or defense-related processes were screened for their ability to express SA-mediated suppression of JA-responsive gene expression. Mutant cev1, which displays constitutive expression of JA and ET responses, appeared to be insensitive to $\mathrm{SA}$-mediated suppression of the JA-responsive marker genes PDF1.2 and VSP2. Accordingly, strong activation of JA and ET responses by the necrotrophic pathogens Botrytis cinerea and Alternaria brassicicola prior to SA treatment counteracted the ability of SA to suppress the JA response. Pharmacological assays, mutant analysis, and studies with the ETsignaling inhibitor 1-methylcyclopropene revealed that ET signaling renders the $\mathrm{JA}$ response insensitive to subsequent suppression by SA. The APETALA2/ETHYLENE RESPONSE FACTOR transcription factor ORA59, which regulates JA/ET-responsive genes such as PDF1.2, emerged as a potential mediator in this process. Collectively, our results point to a model in which simultaneous induction of the JA and ET pathway renders the plant insensitive to future SA-mediated suppression of JA-dependent defenses, which may prioritize the JA/ET pathway over the SA pathway during multi-attacker interactions.

During evolution, plants acquired several layers of defense to protect themselves against a large variety of harmful pathogens and insects. The first layer of defense that attackers encounter is based on preformed structural and chemical barriers (Walters et al. 2007). When attackers overcome this preinva-

Corresponding author: Corné M. J. Pieterse; Telephone: +31 30253 6887; Fax: +31 30253 2837; E-mail: C.M.J.Pieterse@uu.nl

Current address of A. Leon-Reyes: Universidad San Francisco de Quito, USFQ Diego de Robles y Vía Interoceánica (Cumbaya), Quito, Ecuador \& AGROBIOLAB, G. Zaldumbide N49-204 y Luis Calisto Urbanización Dammer II-EL INCA, Quito, Ecuador.

Current address of A. Koornneef: Amsterdam Molecular Therapeutics, P.O. Box 22506, 1100 DA Amsterdam, The Netherlands.

* The $\boldsymbol{e}$-Xtra logo stands for "electronic extra" and indicates that a supplemental table is published online. Figures 5 and 8 appear in color online. sive layer of defense, inducible defense responses can be activated to prevent further pathogen ingress. The phytohormones salicylic acid (SA), ethylene (ET), and jasmonic acid (JA) and its derivatives, collectively called jasmonates (JAs), play pivotal roles in the regulation of these induced defenses (Dong 1998; Grant and Lamb 2006; Van Loon et al. 2006; Loake and Grant 2007; Von Dahl and Baldwin 2007; Howe and Jander 2008; Van Wees et al. 2008; Vlot et al. 2008; Pieterse et al. 2009; Van der Ent et al. 2009). The accumulation of these hormones triggers the activation of a cascade of defense-signaling pathways. However, the final outcome of the defense response is greatly influenced by the production, timing, and composition of the hormonal blend produced (De Vos et al. 2005; Mur et al. 2006; Koornneef et al. 2008; Leon-Reyes et al. 2009; Pieterse et al. 2009). Although there are exceptions, in general, it can be stated that SA-dependent defenses are active against pathogens with a biotrophic lifestyle, whereas JA/ET-dependent defenses are active against pathogens with a necrotrophic lifestyle (Glazebrook 2005) and against insect herbivores (Kessler and Baldwin 2002; Howe and Jander 2008). In addition to SA, JA, and ET, other phytohormones, such as abscissic acid (ABA), auxins, brassinosteroids, cytokinins, and gibberellins, have been shown to affect defense signaling as well; however, their role in plant defense is less well characterized (Pieterse et al. 2009).

In nature, plants often deal with simultaneous or subsequent invasion by multiple pathogens and insects, which can influence the primary induced defense response of the host plant (Van der Putten et al. 2001; Bezemer and Van Dam 2005; Stout et al. 2006; Poelman et al. 2008). Because activation of plant defense mechanisms is associated with ecological fitness costs (Walters and Heil 2007), plants need regulatory mechanisms to effectively adapt to changes in their environment. Recent advances in defense-signaling research revealed that SA, JA, and ET function in a complex network of interconnecting signaling pathways (Pieterse et al. 2009). Interactions between these pathways provide the plant with a powerful regulatory potential that may allow the plant to tailor its defense response to the invaders encountered (Reymond and Farmer 1998; Kunkel and Brooks 2002; Bostock 2005; Pieterse and Dicke 2007).

One of the best-studied examples of signal cross-talk is the antagonistic interaction between SA and JA signaling. Many studies have demonstrated that endogenously accumulating SA antagonizes JA-dependent defenses, thereby prioritizing SA- 
dependent resistance over JA-dependent defense (Bostock 1999; Felton and Korth 2000; Kunkel and Brooks 2002; Thaler et al. 2002; Glazebrook et al. 2003; Beckers and Spoel 2006; Koornneef and Pieterse 2008; Spoel and Dong 2008). For example, induction of the SA pathway in Arabidopsis by exogenous application of SA or infection by the SA-inducing pathogen Pseudomonas syringae suppressed JA signaling and rendered infected leaves more susceptible to the necrotrophic fungus Alternaria brassicicola (Spoel et al. 2007). Similarly, the biotrophic oomycete pathogen Hyaloperonospora arabidopsidis strongly suppressed JA-mediated defenses that were activated upon feeding by caterpillars of the small cabbage white Pieris rapae (Koornneef et al. 2008). Pharmacological experiments with Arabidopsis revealed that JA-responsive marker genes, such as PLANT DEFENSIN 1.2 (PDF1.2) and VEGETATIVE STORAGE PROTEIN2 (VSP2), are highly sensitive to suppression by exogenous application of SA (Spoel et al. 2003; Koornneef et al. 2008). SA-mediated suppression of JA-responsive gene expression was observed in a large number of Arabidopsis accessions collected from very different geographic origins, highlighting the potential significance of this phenomenon in the regulation of induced plant defenses in nature (Koornneef et al. 2008).

Although many reports describe an antagonistic interaction between SA- and JA-dependent signaling, synergistic interactions have been described as well (Schenk et al. 2000; Van Wees et al. 2000; Mur et al. 2006). For example, in Arabidopsis, treatment with low concentrations of methyl JA (MeJA) and SA resulted in a synergistic effect on the JA- and SAresponsive genes PDF1.2 and PATHOGENESIS-RELATED-1 $(P R-1)$, respectively. However, at higher concentrations, the effects were antagonistic, demonstrating that the outcome of the SA-JA interaction is dependent on the relative concentration of each hormone (Mur et al. 2006). Koornneef and associates (2008) demonstrated that timing and sequence of initiation of SA and JA signaling are also important for the outcome of the SA-JA signal interaction. Hence, the kinetics of phytohormone biosynthesis and signaling during the interaction of a plant with its attackers could be highly decisive in the final outcome of the defense response to the attacker encountered. Interplay between defense pathways may provide the plant with a powerful regulatory potential but it is also a possible target for plant attackers to manipulate the plant defense signaling network for their own benefit (Pieterse and Dicke 2007; Robert-Seilaniantz et al. 2007; Walling 2008; Pieterse et al. 2009).

Several proteins with an important regulatory role in SA-JA cross-talk have been identified in Arabidopsis. Mutation or ectopic expression of the corresponding genes were shown to have contrasting effects on SA and JA signaling and on resistance against biotrophs and necrotrophs (Koornneef and Pieterse 2008; Spoel and Dong 2008; Pieterse et al. 2009). The defense regulatory protein NONEXPRESSOR OF PR GENES1 (NPR1) was identified as a key signaling node in the interaction between the SA and JA pathways, because mutant nprl plants were blocked in SA-mediated suppression of JA-responsive genes (Spoel et al. 2003). Recently, it was demonstrated that ET bypasses the need of NPR1 in SA-JA cross-talk, while it enhances NPR1-dependent, SA-responsive $P R-1$ expression (De Vos et al. 2006; Leon-Reyes et al. 2009). These findings indicate that the final outcome of the SA-JA signal interaction during the complex interaction of plants with their attackers can be shaped by ET.

In many cases, ET has been shown to act as an important modulator of plant responses to SA and JAs (Adie et al. 2007; Kazan and Manners 2008). The interaction between ET and JAs is often synergistic. A classic example is the regulation of
PDF 1.2, which requires concomitant activation of the JA and the ET response pathways (Penninckx et al. 1998). Two members of the large plant-specific APETALA2/ETHYLENE RESPONSE FACTOR (AP2/ERF) superfamily of transcription factors, ERF1 and OCTADECANOID-RESPONSIVE $A R A B I-$ DOPSIS59 (ORA59), emerged as principal integrators of the JA and ET signaling pathways (Lorenzo et al. 2003; Pré et al. 2008). The expression of ERF1 and ORA59 is induced by JA or ET and is synergistically activated by both hormones. Overexpression of ORA59 or ERF1 in the JA-insensitive mutant coil-1, and overexpression of ERF1 in the ethylene insensitive 2 mutant ein $2-1$, constitutively activated the $P D F 1.2$ gene, indicating that these transcription factors are important nodes of convergence of the JA and ET signaling pathways (Lorenzo et al. 2003; Pré et al. 2008). Ectopic expression of ERF1 and ORA59 was shown to enhance resistance of Arabidopsis to necrotrophic pathogens such as Botrytis cinerea and Plectosphaerella cucumerina, as well as Fusarium oxysporum (Berrocal-Lobo et al. 2002; Berrocal-Lobo and Molina 2004; Pré et al. 2008). Moreover, silencing of ORA59 was shown to enhance susceptibility to $B$. cinerea (Pré et al. 2008), indicating that these AP2/ERF-type transcription factors play an important role in the regulation of JA/ET-dependent defenses. Another point of convergence between JA and ET signaling is CONSTITUTIVE EXPRESSOR OF VSP1 (CEV1) (Ellis and Turner 2001), which is also known as cellulose synthase CeSA3 (Ellis et al. 2002b). Arabidopsis cev1 mutants constitutively express JA- and ET-dependent responses, as evidenced by high PDF1.2 and VSP2 transcript levels and enhanced pathogen resistance (Ellis and Turner 2001; Ellis et al. 2002a).

In this study, we searched for novel components involved in the regulation of SA-JA cross-talk. Because plant defenses are controlled by a signaling network in which various defenserelated signaling pathways are interconnected, we screened 43 well-characterized Arabidopsis mutants and transgenic lines with an altered phytohormone or defense-related phenotype for their ability to display SA-mediated suppression of JAresponsive expression of $P D F 1.2$ or $V S P 2$. Here, we show that mutant cevl is impaired in SA-JA cross-talk. Moreover, we provide evidence that the synergistic effect of ET on JA signaling is responsible for counteracting the antagonistic effect of SA on JA signaling, and that the AP2/ERF transcription factor ORA59 is an important player in the regulation of this process.

\section{RESULTS}

\section{Screening for novel key players in SA-JA cross-talk.}

To investigate the interaction between SA and JA signaling, we used a previously described SA-JA cross-talk assay (Spoel et al. 2003; Koornneef et al. 2008; Leon-Reyes et al. 2009). In brief, 5-week-old Arabidopsis plants were treated with $1 \mathrm{mM}$ SA, $0.1 \mathrm{mM}$ MeJA, or a combination of these treatments, after which the expression of the SA-responsive marker gene $P R-1$ and the JA-responsive marker genes $P D F 1.2$ and $V S P 2$ was analyzed. In wild-type Col-0 plants, the JA-responsive marker genes are typically suppressed by SA whereas, in mutant nprl1 plants, SA-JA cross-talk is blocked (Fig. 1A). Plant defense responses are regulated by a complex network of interconnecting signaling pathways (Kazan and Manners 2008; Koornneef and Pieterse 2008; Spoel and Dong 2008; Pieterse et al. 2009); therefore, we attempted to identify novel key players in SA-JA cross-talk by screening 43 well-characterized hormone- and defense-related mutants and transgenic lines (Supplementary Table 1) for their ability to display SA-mediated suppression of JA-responsive gene expression. The Arabidopsis genotypes used in this screen (Fig. 1B) were affected in biosynthesis of or the response to the phytohormones SA, JAs, ET, ABA, 
auxin, or gibberellin, or in redox regulation or production of the antimicrobial phytoalexin camalexin. Five-week-old plants were treated with MeJA or a combination of MeJA and SA. Then, 23 $\mathrm{h}$ later, leaf tissue was harvested and the expression of PDF1.2 was assessed by Northern blot analysis and quantified using a Phosphor imager. For those genotypes in which PDF1.2 was not expressed, we analyzed the expression level of the JAresponsive marker gene $V S P 2$ (Fig. 1B, mutants indicated with $\Delta)$. Results of the SA-JA cross-talk experiments with the 43 Arabidopsis genotypes are depicted in Figure 1B. In all geno- types tested, the single MeJA treatment resulted in the induction of PDF1.2 or VSP2 (transcript levels set at $100 \%$ ). SA suppressed MeJA-induced $P D F 1.2$ expression by 70 to $85 \%$ in wild-type Col-0, Col-5, Ler-0, and Ws-0 plants, confirming previous findings (Koornneef et al. 2008). In the SA-related mutants nprl-1 and nprl-2, and transgenic SA-degrading NahG plants, SA did not suppress MeJA-induced PDF1.2 expression, corroborating previous findings that SA-activated NPR1 is required for SA-JA cross-talk (Spoel et al. 2003). NPR1 was shown to interact with TGA transcription factors, which play an
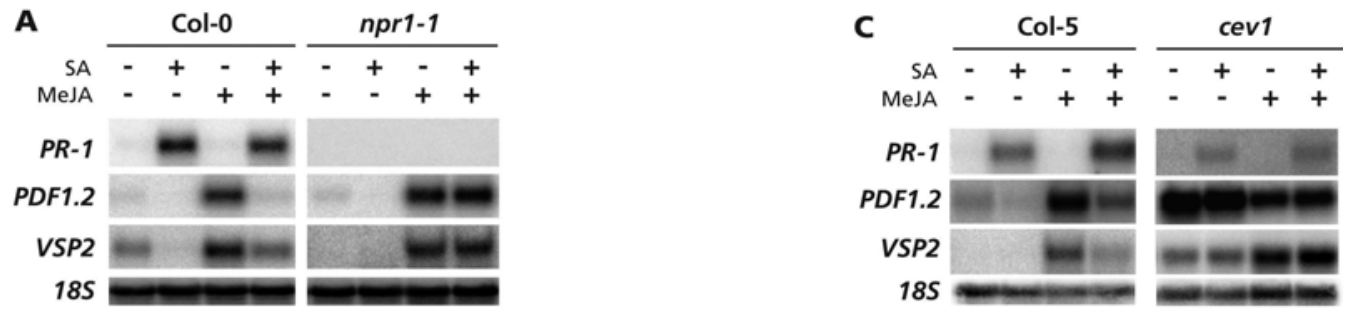

B
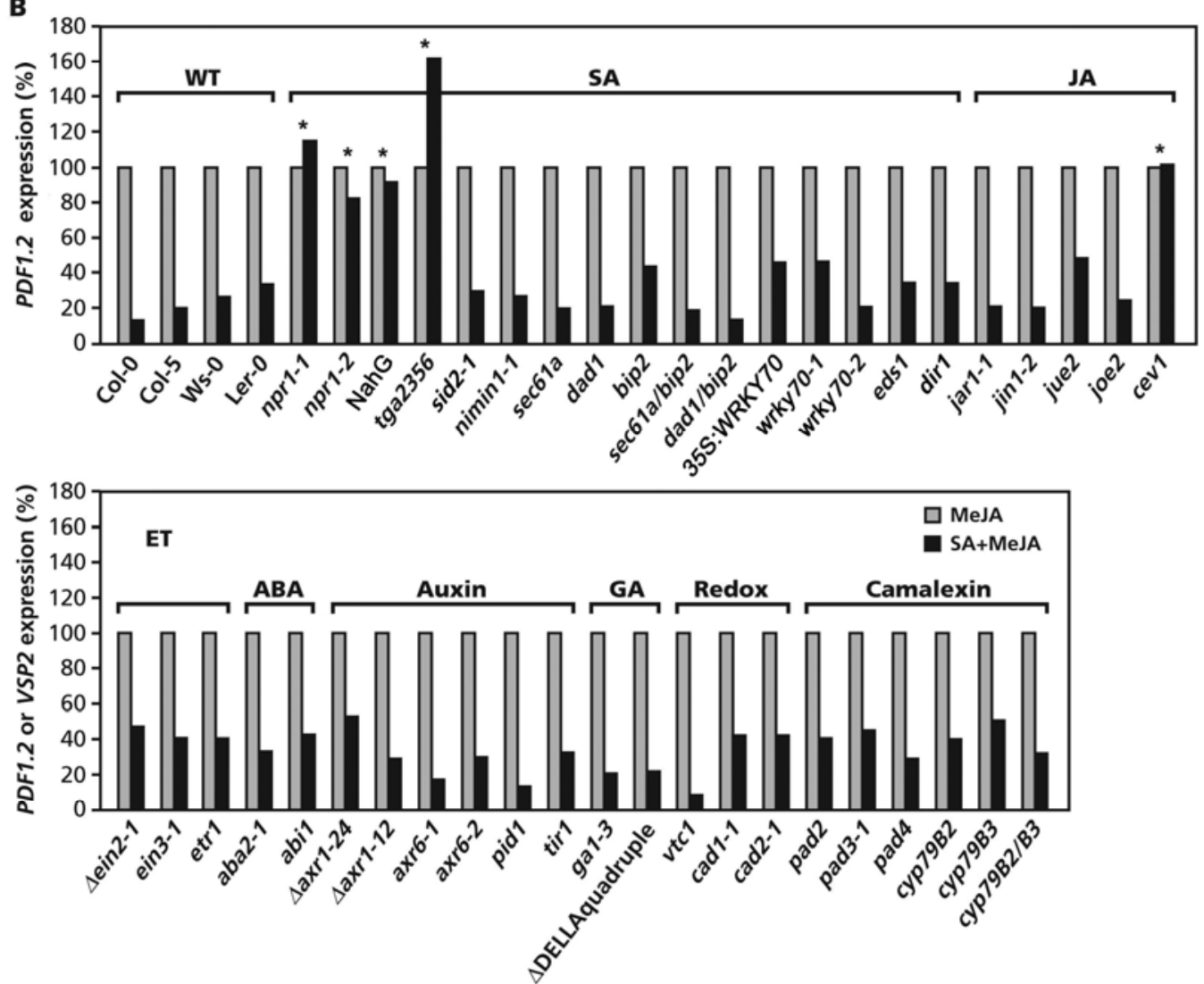

Fig. 1. Quantification of salicylic acid-jasmonic acid (SA-JA) cross-talk in Arabidopsis genotypes affected in hormone- or defense-related responses. A, Northern blot analysis of the SA-responsive gene PR-1 and the JA-responsive genes PDF1.2 and VSP2 in Col-0 and nprl-1 after treatment with 1 mM SA, $0.1 \mathrm{mM}$ methyl jasmonate (MeJA). or a combination of both chemicals. Leaf tissue was harvested $24 \mathrm{~h}$ after chemical treatment. Equal loading of RNA samples was checked using a probe for $18 S$ ribosomal (r)RNA. B, Analysis of PDF1.2 or VSP2 ( $\triangle$ ) gene expression in 5-week-old Arabidopsis genotypes after treatment with $0.1 \mathrm{mM}$ MeJA or a combination of $0.1 \mathrm{mM}$ MeJA and $1 \mathrm{mM}$ SA. Leaf tissue was harvested $24 \mathrm{~h}$ after chemical treatment. Signal intensities on Northern blots were quantified using a Phosphor imager. PDF1.2 and VSP2 ( $\Delta$ ) transcript levels in the single MeJA treatments were set at 100\%. Asterisks indicate genotypes in which SA-mediated suppression of JA-responsive gene expression in the combination treatment is less than 50\% of that in the single MeJA treatment. SA-related genotypes (genetic background in parenthesis): nprl-1 (Col-0), nprl-2 (Col-0), NahG (Col-0), tga2-1/tga3-1/tga5-1/tga6-1 quadruple mutant (Col-0), sid2-1 (Col-0), nimin1-1 (Col-0), sec61a (Col-0), dad1 (Col-0), bip2 (Col-0), sec61a/bip2 (Col-0), dad1/bip2 (Col-0), 35S:WRKY70 (Col-0), wrky70-1 (Col-0), wrky70-2 (Col-0), eds1 (Ler-0), dir1 (Ws-0); JA-related genotypes: jar1-1 (Col-0), jin1-2 (Col-0), jue2 (Col-0), joe 2 (Col-0) and cev1 (Col-5); ET-related genotypes: ein2-1 (Col-0), ein3-1 (Col-0) and etr1 (Col-0); abscisic acid-related genotypes aba2-1 (Col-0) and abil (Ler-0); auxin-related genotypes: axr1-24 (Col-0), axr1-12 (Col-0), axr6-1 (Col-0), axr6-2 (Col-0), pid1 (Ler-0), and tirl-1 (Col-0); gibberellin (GA)related genotypes: gal-3 (Ler-0) and DELLA-quadruple (Ler-0); redox-related genotypes: vtcl (Col-0), cad1-1 (Col-0) and cad2-1 (Col-0); camalexinrelated genotypes: pad2 (Col-0), pad3-1 (Col-0), pad4 (Col-0), cyp79B2 (Ws-0), cyp79B3 (Ws-0), and cyp79B2B3 (Ws-0). C, Northern blot analysis of the $P R-1, P D F 1.2$, and VSP2 transcript levels in 5-week-old Col-5 and cev1 plants that were or were not treated with $1 \mathrm{mM} \mathrm{SA}, 0.1 \mathrm{mM}$ MeJA, or a combination of both chemicals. Leaf tissue was harvested $24 \mathrm{~h}$ after chemical treatment for RNA analysis. Equal loading of RNA samples was checked using a probe for $18 S$ rRNA. 
important role in the regulation of SA-responsive $P R$ genes (Després et al. 2000; Dong 2004; Kesarwani et al. 2007). The quadruple mutant tga2-1/tga3-1/tga5-1/tga6-1, which is impaired in four of the seven TGA transcription factors that interact with NPR1 and which is affected in its ability to mount systemic acquired resistance (SAR) and $P R$ gene expression (Kesarwani et al. 2007), was also incapable of suppressing JAresponsive gene expression by SA (Fig. 1B). This is in line with experiments performed by Ndamukong and associates (2007), who showed that the triple mutant tga2-1/tga5-1/tga6-1 is blocked in its ability to display SA-JA cross-talk. All other genotypes with an aberrant phenotype in SA signaling displayed near wild-type levels of SA-JA cross-talk, suggesting that the corresponding proteins have no major effect on the antagonistic effect of SA on JA signaling.

Of all other genotypes tested, only mutant cevl was blocked in SA-JA cross-talk (Fig. 1B). Mutant cevl was originally identified as a mutant with a constitutively activated JA and ET signaling pathway (Ellis and Turner 2001). Indeed, both $P D F 1.2$ and VSP2 were constitutively expressed in untreated cev1 plants (Fig. 1C). In both wild-type Col-5 and mutant cevl plants, the SA treatment triggered the expression of $P R-1$. In Col-5 plants, MeJA-induced PDF1.2 and VSP2 expression was strongly suppressed by SA when SA and MeJA were simultaneously applied. However, in the cevl mutant, SA had no negative effect on the transcript levels of PDF1.2 and VSP2 (Fig. 1C). These results point to a model in which stimulation of both JA and ET signaling prior to activation of the SA response renders Arabidopsis plants insensitive to SA-mediated suppression of JA-responsive gene expression. This hypothesis is further investigated in this study.

\section{ET plays a dominant role}

\section{in counteracting $\mathrm{SA}$-mediated suppression of PDF1.2.}

To investigate whether JA or ET signaling is responsible for neutralizing the antagonistic effect of SA on JA signaling, we made use of mutant constitutive allene oxide synthasel (casl) (Kubigsteltig and Weiler 2003), which exhibits a constitutive JA response, and mutant constitutive triple responsel (ctrl) (Kieber et al. 1993), which displays a constitutive ET response. Five-week-old plants were subjected to the pharmacological
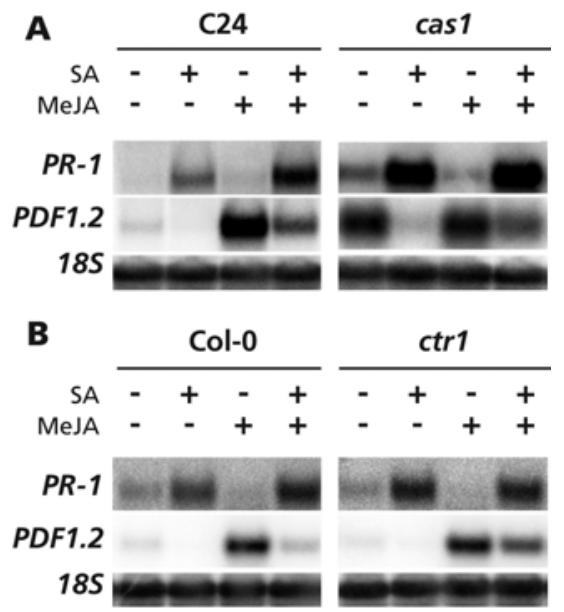

Fig. 2. Salicylic acid (SA)-mediated suppression of PDF1.2 in Arabidopsis mutants cas 1 and ctr1. Northern blot analysis of $P R-1$ and PDF1.2 transcript levels in A, C24 and casl (constitutive jasmonic acid [JA] response) plants and $\mathbf{B}$, Col-0 and $\operatorname{ctrl}$ (constitutive ET response) plants that were or were not treated with $1 \mathrm{mM}$ SA, $0.1 \mathrm{mM}$ methyl jasmonate (MeJA), or a combination of both chemicals. Leaf tissue was harvested 24 $\mathrm{h}$ after chemical treatment for RNA analysis. Equal loading of RNA samples was checked using a probe for $18 S$ ribosomal RNA.
SA-JA cross-talk assay. As expected, mutant cas 1 plants (in C24 background) constitutively expressed PDF1.2 following mock treatment (Fig. 2A). Treatment with SA or SA and MeJA suppressed the expression of PDF1.2 to a level that was comparable with that observed in wild-type C24 plants, suggesting that constitutive expression of JA-dependent responses alone has no negative effect on the ability of SA to suppress JA-responsive gene expression. On the other hand, constitutive expression of the ET response in mutant ctrl (in Col-0 background) strongly reduced the suppressive effect of SA on MeJA-induced PDF1.2 expression (Fig. 2B). These results suggest that ET plays a role in counteracting the suppressive effect of SA on MeJA-induced expression of PDF1.2.

To corroborate the genetic evidence obtained with cas 1 and ctrl, we followed a pharmacological approach in which we stimulated the JA response with increasing concentrations of MeJA or with $0.1 \mathrm{mM}$ MeJA and increasing concentrations of the ET precursor 1-aminocyclopropane-1-carboxylic acid (ACC). First, Col-0 plants were treated with $0.1,0.5$, 1.0, or 2.0 $\mathrm{mM}$ MeJA. The plants were allowed to activate the JA response for $24 \mathrm{~h}$, after which $1 \mathrm{mM}$ SA was applied to the leaves. At 24 $\mathrm{h}$ after SA treatment, PDF1.2 transcript levels were assessed to monitor the antagonistic effect of SA on JA-responsive gene expression. SA suppressed MeJA-induced PDF1.2 expression for all MeJA concentrations used (Fig. 3A). There was no clear difference between the levels of PDF1.2 suppression when high or low MeJA concentrations were used, suggesting that the strength of the activated JA response does not affect the capacity of SA to suppress JA signaling.

To investigate the effect of ET, 5-week-old plants were treated with $0.1 \mathrm{mM}$ MeJA and either $0.25,1.0$, or $2.5 \mathrm{mM}$ ACC. One day later, the plants were treated with SA and, $24 \mathrm{~h}$ later, harvested for RNA analysis. SA strongly suppressed MeJA-induced PDF1.2 transcription in the presence of up to 1 $\mathrm{mM}$ ACC (Fig. 3B). However, when $2.5 \mathrm{mM}$ ACC was applied, the antagonistic effect of SA on MeJA-induced PDF1.2 expression was strongly reduced. These data support the genetic evidence provided in Figure 2 that, under conditions in which JA- and ET-dependent responses are simultaneously expressed, ET is predominantly responsible for neutralizing the antagonistic effect of SA on JA-responsive gene expression.

\section{Pathogen-induced JA/ET signaling renders plants insensitive to $\mathrm{SA}$-mediated suppression of JA-responsive gene expression.}

Our mutant and pharmacological analysis suggested that simultaneous activation of the JA and ET response prior to induction of the SA response renders Arabidopsis plants insensitive to SA-mediated suppression of JA signaling. In a biological context, this would mean that plants that are infected with a JA/ET-inducing pathogen become insensitive for future SAmediated suppression of JA-dependent defenses. To test this hypothesis, we triggered the JA/ET-response in Col-0 plants by inoculating 5-week-old plants with the necrotrophic fungus $B$. cinerea, which has previously been shown to activate JA/ETdependent responses (Thomma et al. 2000, 2001). At $24 \mathrm{~h}$ after inoculation (early stage of infection), only mild disease symptoms were visible, whereas $48 \mathrm{~h}$ after inoculation (late stage of infection), the plants were severely diseased (data not shown). Plants with an early or late stage of $B$. cinerea infection were treated with $1 \mathrm{mM} \mathrm{SA}$ and, $24 \mathrm{~h}$ later, the ability of SA to suppress $B$. cinerea-induced $P D F 1.2$ expression was assessed. In Col-0 plants with an early stage of $B$. cinerea infection, pathogen-induced PDF1.2 expression was suppressed by SA (Fig. 4). However, in plants with a late stage of $B$. cinerea infection, this suppression was not apparent (Fig. 4). Instead, SA seemed to act synergistically on the level of $B$. cinerea-induced PDF1.2 tran- 
scription. These results suggest that severe infection with a pathogen that triggers JA- and ET-dependent responses can counteract the ability of SA to suppress JA signaling.

To further substantiate this finding, we used the necrotrophic fungus $A$. brassicicola to stimulate JA and ET responses. Previously, we demonstrated that $A$. brassicicola strongly activates JA and ET biosynthesis and signaling in Arabidopsis without stimulating the SA pathway (De Vos et al. 2005). We made use of two Arabidopsis genotypes with different levels of resistance against this pathogen: Col-0, which is resistant, and the phytoalexin-deficient mutant pad3-1, which is susceptible (Thomma et al. 1999). Upon inoculation with A. brassicicola, Col-0 developed necrotic lesions that remained contained to the inoculation site, whereas pad3-1 plants developed rapidly spreading lesions (Fig. 5A). Susceptible pad3-1 plants accumulated significantly higher levels of ET upon $A$. brassicicola infection than resistant Col-0 plants (Fig. 5B). In the absence of SA, A. brassicicola induced similar levels of PDF1.2 transcription in Col-0 and pad3-1 at 3, 24, 48, and 72 $\mathrm{h}$ after inoculation (Fig. 5C). Application of SA at 3, 24, 48, or $72 \mathrm{~h}$ after inoculation strongly suppressed $A$. brassicicolainduced PDF 1.2 expression in Col-0. However, in pad3-1, the antagonistic effect of SA on A. brassicicola-induced PDF1.2

A
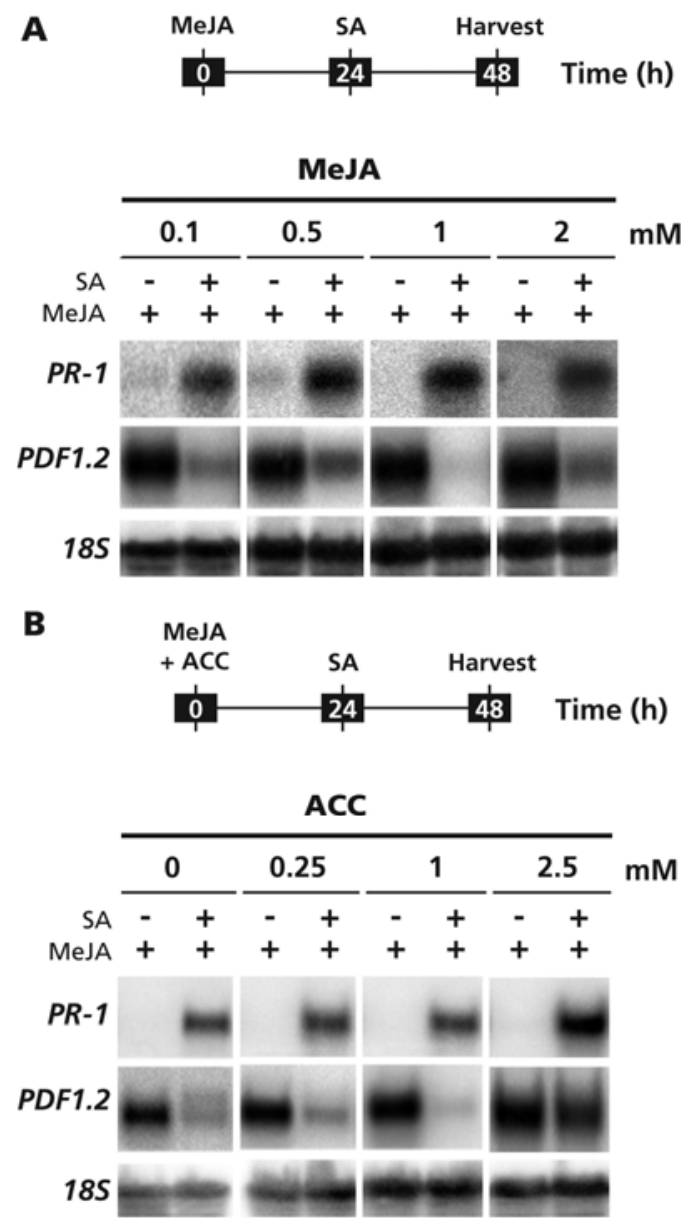

Fig. 3. Effect of increasing concentrations of methyl jasmonate (MeJA) and 1-aminocyclopropane-1-carboxylic acid (ACC) on salicylic acid (SA)mediated suppression of MeJA-induced PDF1.2 expression. Northern blot analysis of $P R-1$ and $P D F 1.2$ transcript levels in Col-0 plants that were treated with $\mathbf{A}$, increasing concentrations of $\mathrm{MeJA}(0.1,0.5,1.0$, or 2.0 $\mathrm{mM})$ or $\mathbf{B}, 0.1 \mathrm{mM}$ MeJA and increasing concentrations of ACC $(0,0.25$, 1.0 , or $2.5 \mathrm{mM}$ ). Then, $24 \mathrm{~h}$ later, plants were treated with $1 \mathrm{mM}$ SA or received a mock treatment. Leaf tissue was harvested $24 \mathrm{~h}$ after application of SA for RNA analysis. Equal loading of RNA samples was checked using a probe for $18 S$ ribosomal RNA. expression was notably reduced at the time points 24,48 , and $72 \mathrm{~h}$. At these time points, the infected pad3-1 plants produced large amounts of ET, again suggesting that simultaneous activation of the JA and ET response renders the plant tissue insensitive to subsequent suppression of JA signaling by SA.

\section{1-Methylcyclopropene restores sensitivity}

to SA-mediated suppression of PDF1.2.

Our genetic and pharmacological experiments suggested that ET plays a dominant role in counteracting the antagonistic effect of SA on JA signaling; therefore, we tested whether inhibition of ET signaling in A. brassicicola-infected pad3-1 plants can restore the sensitivity of the tissue to SA-mediated suppression of JA signaling. To this end, we performed SA-JA cross-talk assays with the ET signaling inhibitor 1-methylcyclopropene (1-MCP). Five-week-old pad3-1 plants were treated with 1 -MCP at $1 \mu \mathrm{l}$ liter $^{-1}$ or air for the duration of the experiment. At $2 \mathrm{~h}$ after the start of the 1-MCP treatment, the plants were inoculated with $A$. brassicicola. At 24, 48, and $72 \mathrm{~h}$ after inoculation, the plants were or were not treated with $1 \mathrm{mM} \mathrm{SA}$ and, 1 day later, leaf tissue was harvested for RNA analysis. In the absence of 1-MCP (Fig. 6, white bars), the antagonistic effect of SA on A. brassicicola-induced PDF1.2 expression was visible at $24 \mathrm{~h}$ after inoculation (approximately 40\% suppression) but, at the 48- and 72-h time points, the suppressive effect of SA was clearly reduced (to approximately 25 and $10 \%$ suppression at 40 and $72 \mathrm{~h}$, respectively). In the presence of 1-MCP, PDF1.2 messenger (m)RNA levels were substantially lower in $A$. brassicicola-inoculated plants. Because JA and ET signaling are co-required for PDF1.2 expression (Penninckx et al. 1998), this observation indicated that 1-MCP effectively inhibited the ET pathway. Notably, in plants treated with 1-MCP (Fig. 6, black bars), SA-mediated suppression of A. brassicicola-induced PDF1.2 was much more pronounced at all time points tested than in the nontreated plants, confirming that ET produced during the Arabidopsis-A. brassicicola interaction counteracts the antagonistic effect of SA on JA signaling.

\section{The AP2/ERF transcription factor gene ORA59 is a dominant player in ET-mediated inhibition of SA-JA antagonism.}

To identify possible molecular mechanisms underlying the observed interplay between ET, JA, and SA signaling, we in-

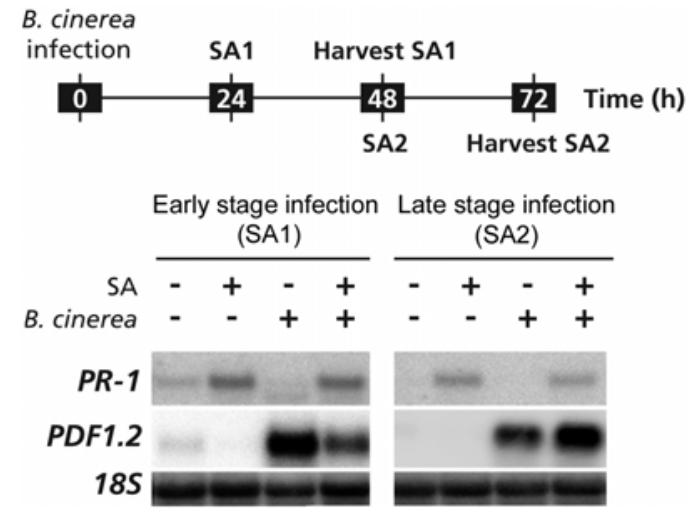

Fig. 4. Botrytis cinerea infection renders Arabidopsis plants insensitive to salicylic acid (SA)-mediated suppression of PDF1.2 expression. Northern blot analysis of $P R-1$ and PDF1.2 transcript levels in Col-0 plants that were inoculated with the necrotrophic pathogen $B$. cinerea. After 24 and $48 \mathrm{~h}$, plants had developed mild (early stage infection) and severe (late stage infection) disease symptoms, respectively. At 24 (SA1) or $48 \mathrm{~h}$ (SA2) after inoculation, plants were or were not treated with $1 \mathrm{mM} \mathrm{SA}$ and $24 \mathrm{~h}$ later harvested for RNA analysis. Equal loading of RNA samples was checked using a probe for $18 S$ ribosomal RNA. 
vestigated the role of the AP2/ERF transcription factor ORA59 in this phenomenon. Previously, ORA59 was found to function as an important integrator of the JA and ET signaling pathways (Pré et al. 2008). Overexpression of ORA59 in JA-insensitive coil-1 resulted in high levels of $P D F 1.2$ expression whereas silencing of ORA59 blocked PDF1.2 transcription (Pré et al. 2008), indicating that ORA59 is a dominant regulator of JA/ET-responsive genes that functions downstream of the Fbox protein COI1. To investigate whether the inhibitory effect of ET on SA-JA antagonism is regulated at the level of ORA59, we analyzed the expression of ORA59 in the SA-JA cross-talk assay in the presence or absence of gaseous ET. Col0 plants were pretreated with gaseous ET at $10 \mu \mathrm{liter}{ }^{-1}$ or air for $6 \mathrm{~h}$. Thereafter, plants were or were not treated with $1 \mathrm{mM}$ SA, $0.1 \mathrm{mM}$ MeJA, or a combination of both chemicals and placed back in the ET or air environment. Then, $24 \mathrm{~h}$ later, ORA59 and PDF1.2 expression was assessed. In the absence of additional ET, MeJA mildly activated ORA59, but this coincided with high expression levels of PDF1.2 (Fig. 7). In the ETtreated plants, ORA59 transcripts accumulated in response to all four treatments. PDF1.2 followed the expression pattern of ORA59, confirming previous findings that ORA59 expression is activated by ET and plays a central role in the regulation of PDF1.2 gene expression (Pré et al. 2008). In the absence of additional ET, SA strongly suppressed MeJA-induced ORA59 and PDF 1.2. However, in ET-treated plants, the antagonistic effect of SA on MeJA-responsive ORA59 and PDF1.2 expression was blocked. These results suggest that the inhibitory effect of ET on SA-JA antagonism is regulated via the transcription factor ORA59.

To corroborate these findings, we induced the JA and ET response by inoculating pad3-1 plants with $A$. brassicicola (Fig. 7). Then, $48 \mathrm{~h}$ later, the plants were treated or not with SA. A. brassicicola induced the expression of ORA59 in pad31 plants. Similar to what we observed for PDF1.2 (Fig. 5), SA was unable to suppress $A$. brassicicola-induced ORA59 transcription in high ET-producing pad3-1 plants. Again, PDF1.2 showed the same expression pattern as ORA59 and was not suppressed by SA. Together, these results suggest that ORA59 plays a role in mediating the inhibitory effect of ET on SA-JA cross-talk.

To provide further evidence for the role of ORA59 in ETmediated inhibition of SA-JA cross-talk, we subjected the transgenic ORA59-overexpressing line 35S:ORA59 (Pré et al. 2008 ) to the SA-JA cross-talk assay. Transgenic 35S:ORA59 plants constitutively expressed ORA59 and showed high constitutive levels of PDF1.2 mRNA (Fig. 7), confirming previous findings (Pré et al. 2008). Application of SA to 35S:ORA59

A

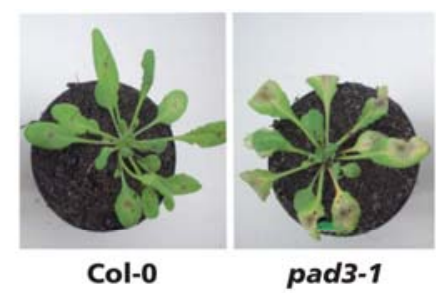

B
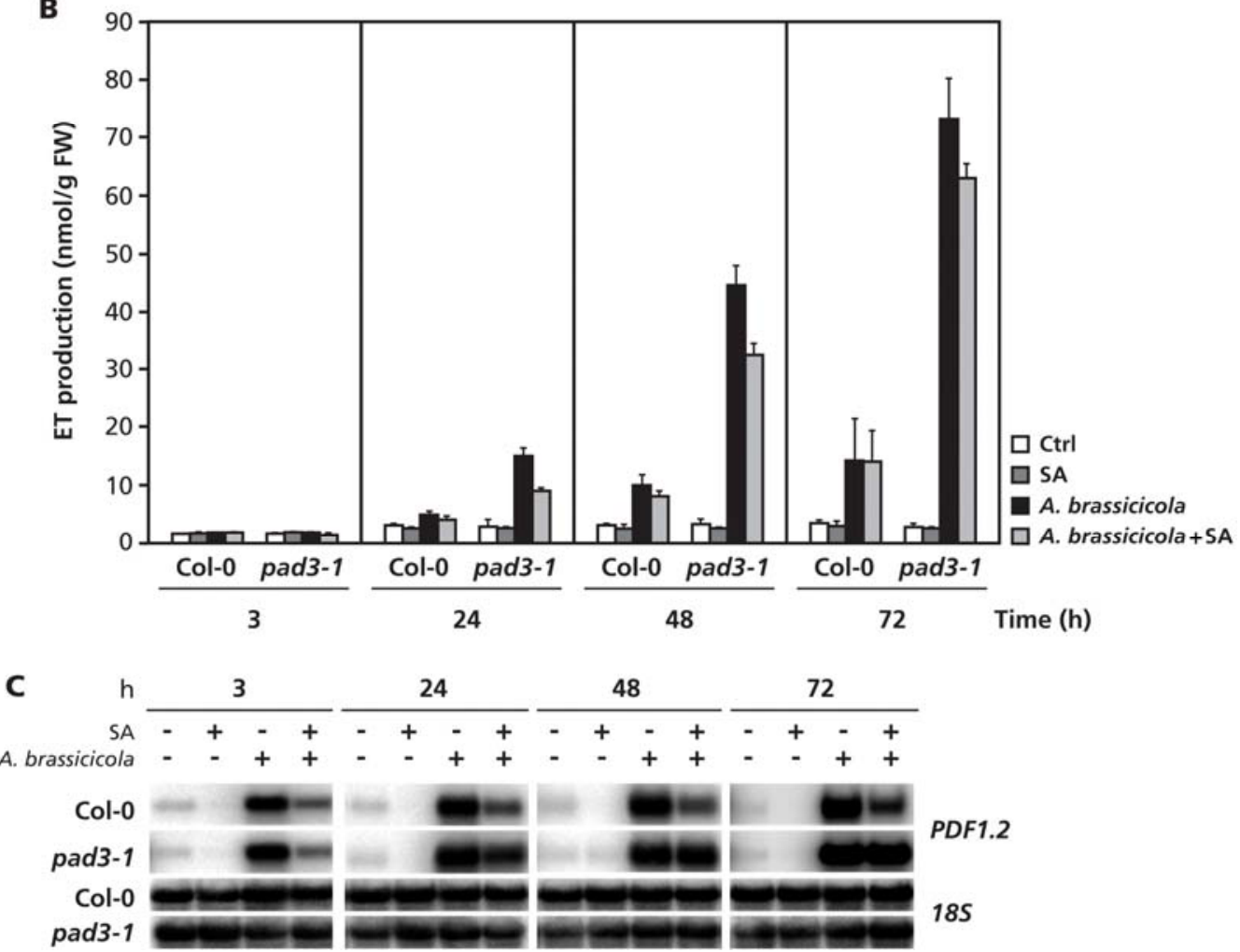

Fig. 5. High ethylene (ET) levels in susceptible Alternaria brassicicola-infected pad3-1 plants correlate with the inability of salicylic acid (SA) to suppress A. brassicicola-induced PDF1.2 expression. A, Disease symptoms in resistant Col-0 and susceptible pad3-1 plants, 5 days after inoculation with A. brassicicola. B, Kinetics of ET production in Col-0 and pad3-1 plants after inoculation with A. brassicicola and treatment with SA. C, Northern blot analysis of PDF1.2 transcript levels in Col-0 and pad3-1 plants that were inoculated with A. brassicicola and treated with $1 \mathrm{mM} \mathrm{SA}$ at 3, 24, 48, and $72 \mathrm{~h}$ postinoculation. Leaf tissue was harvested for RNA analysis $24 \mathrm{~h}$ after application of SA. Equal loading of RNA samples was checked using a probe for $18 S$ ribosomal RNA. 
plants did not repress $P D F 1.2$ transcript levels, indicating that overexpression of ORA59 blocks the antagonistic effect of SA on JA-responsive gene expression.

\section{DISCUSSION}

ET counteracts the antagonistic effect of $S A$ on JA-responsive gene expression.

Previously, we demonstrated that exogenous application of SA suppresses JA-responsive genes, such as PDF1.2 and VSP2 (Van Wees et al. 1999; Spoel et al. 2003; Koornneef et al. 2008; Leon-Reyes et al. 2009). Also, induction of the SA response upon infection by the biotrophic oomycete $H$. arabidopsidis antagonized JA-responsive gene expression (Koornneef et al. 2008), suggesting that, during multi-attacker interactions, the SA response is prioritized over the JA response in Arabidopsis. However, in the abovementioned studies, the SA response was either activated at the same time as or prior to the activation of the JA/ET response. In the present study, we provide evidence that stimulation of the ET pathway prior to the activation of the SA response can render the plant insensitive to SA-mediated suppression of JA signaling. First, we showed that the cevl mutant, which constitutively expresses JA and ET responses, was insensitive to SA-mediated suppression of PDF1.2 expression (Fig. 1). Similarly, induction of the JA and ET response upon inoculation with the necrotrophic pathogens $B$. cinerea and A. brassicicola resulted in insensitivity of the leaf tissue to suppression of the JA response by SA (Figs. 4 and 5). Analysis of the constitutive JA response mutant cas 1 and the constitutive ET response mutant ctrl revealed that ET plays a dominant role in counteracting the antagonistic effect of SA on JA-responsive gene expression (Fig. 2). This was corroborated by the observation that application of high concentrations of ACC similarly neutralized the antagonistic effect

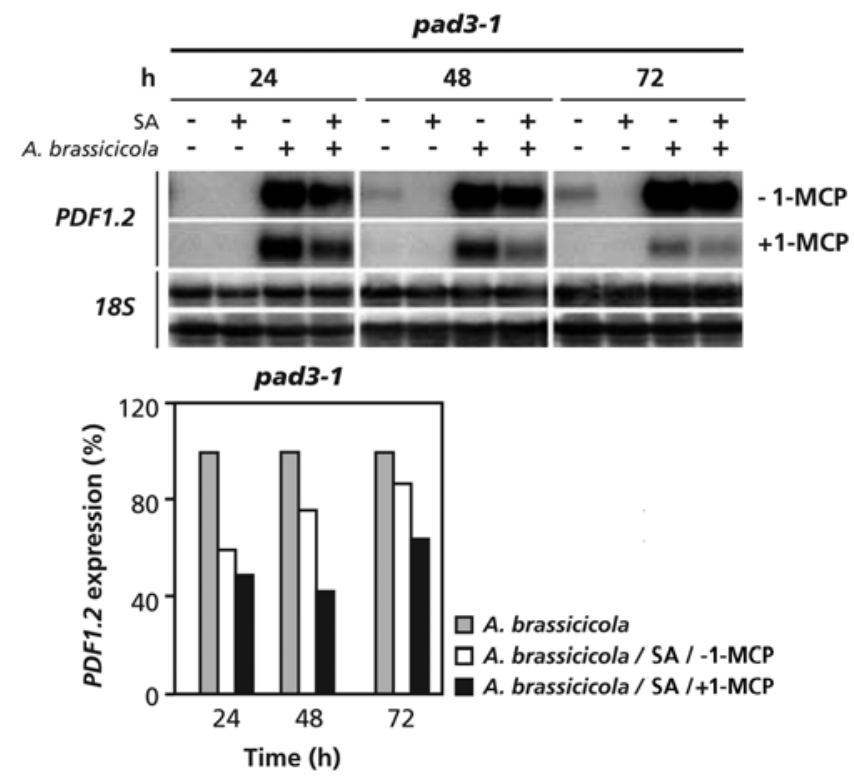

Fig. 6. Inhibition of ethylene (ET) signaling with 1-methylcyclopropene (1-MCP) restores salicylic acid (SA)-mediated suppression of Alternaria brassicicola-induced PDF1.2 expression. Northern blot analysis of PDF1.2 transcript levels in pad3-1 plants that were pretreated with the ET inhibitor 1-MCP $\left(1 \mu \mathrm{l}\right.$ liter $\left.^{-1}\right)$ or air and inoculated with $A$. brassicicola. At 24,48 , and $72 \mathrm{~h}$ after inoculation, plants were or were not treated with 1 $\mathrm{mM} \mathrm{SA}$ and, $24 \mathrm{~h}$ later, leaf tissue was harvested for RNA analysis. Equal loading of RNA samples was checked using a probe for $18 S$ ribosomal RNA. Signal intensities were quantified using a Phosphor imager (bottom panel). PDF1.2 transcript levels in A. brassicicola-inoculated plants that were not treated with SA were set to $100 \%$. of SA on JA-responsive gene expression (Fig. 3). In addition, the ET signaling inhibitor 1-MCP attenuated the effect of pathogen-induced ET on SA-JA cross-talk during the ArabidopsisA. brassicicola interaction. Thus, it can be concluded that activation of the ET pathway renders Arabidopsis plants insensitive to future SA-mediated suppression of the JA response.

\section{ORA59 is an important regulator in counteracting} SA-mediated antagonism of JA signaling.

The interplay between JA and ET is one of the best-studied examples of synergistic defense signal interactions (Penninckx et al. 1998; Broekaert et al. 2006; Adie et al. 2007). Simultaneous activation of the JA and ET response results in a boosted expression pattern of JA/ET-responsive genes, such as PDF1.2 (Penninckx et al. 1998). The AP2/ERF transcription factors ERF1 and ORA59 have been described as important integrators of the JA and ET pathways (Lorenzo et al. 2003; Lorenzo and Solano 2005; Pré et al. 2008). In the PDF1.2-overexpressing mutant cev1, ORA59 was constitutively expressed (data not shown). Also, MeJA- and A. brassicicola-induced PDF1.2 correlated with enhanced ORA59 gene expression (Fig. 7), supporting previous findings that ORA59 is an important transcriptional regulator of JA/ET-responsive gene expression (Pré et al. 2008). In this article, we show that overexpression of ORA59 in stable 35S:ORA59 transformants resulted in constitutive $P D F 1.2$ expression, which could not be suppressed by SA (Fig. 7). Thus, we conclude that, in addition to its role in the integration of the JA and ET pathway, ORA59 also plays an important role in counteracting SA-mediated suppression of JA/ET-responsive genes such as PDF1.2.

When the SA pathway is activated prior to or at the same time as the JA pathway, SA suppresses ORA59 gene expression, resulting in a repression of JA/ET-responsive genes such as PDF 1.2. However, when the JA/ET-pathway is already activated, SA can no longer suppress the JA/ET response. This raises the question: how does ORA59 counteract the antagonistic effect of SA on JA-responsive gene expression? Previously, it was demonstrated that ORA59 binds to the GCC-box motif in the PDF1.2 promoter (Zarei 2007). A plausible explanation for the neutralizing effect of ORA59 on SA-JA antagonism is that the suppressive effect of SA on JA-responsive gene expression functions through the GCC-box. In this scenario, SA induces an inhibitor that binds to the GCC box, thereby blocking this site for positive regulators of JA-respon-

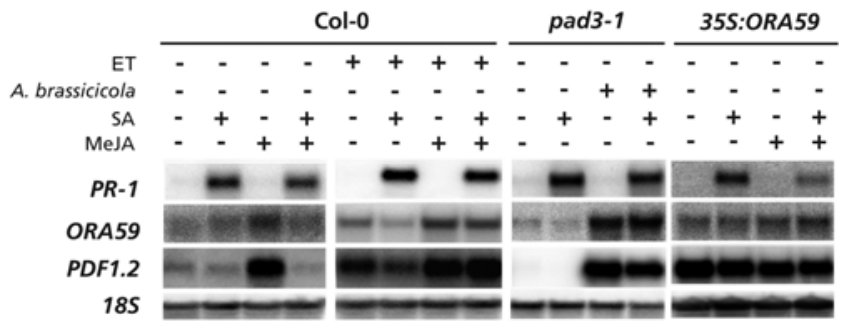

Fig. 7. Role for the APETALA2/ETHYLENE RESPONSE FACTOR transcription factor in counteracting salicylic acid (SA)-mediated suppression of jasmonic acid (JA)-responsive gene expression. Northern blot analysis of PR-1, ORA59, and PDF1.2 transcript levels in 5-week-old Col-0, pad31, and 35S:ORA59 plants. Wild-type Col-0 plants were treated with ethylene (ET) by applying gaseous ET at $10 \mu 1$ liter $^{-1}$ or air as a control. At $6 \mathrm{~h}$ after the start of the ET treatment, Col-0 plants were or were not treated with $1 \mathrm{mM} \mathrm{SA}, 0.1 \mathrm{mM}$ methyl jasmonate (MeJA), or a combination of both chemicals. Susceptible pad3-1 plants were inoculated with the fungus Alternaria brassicicola and, $48 \mathrm{~h}$ later, treated or not with $1 \mathrm{mM} \mathrm{SA}$. Transgenic 35S:ORA59 plants were treated with $1 \mathrm{mM} \mathrm{SA}, 0.1 \mathrm{mM}$ MeJA, or a combination of both chemicals. Leaf tissue of all treatments was harvested $24 \mathrm{~h}$ after the SA treatment for RNA analysis. Equal loading of RNA samples was checked using a probe for $18 S$ ribosomal RNA. 
sive gene expression, such as ORA59. When ORA59 is strongly expressed prior to activation of the SA response, it out-competes the putative SA-induced inhibitor, resulting in insensitivity to SA-mediated suppression of JA-responsive gene expression (Fig. 8). Alternatively, SA may induce a repressor of ORA59 activity; for example, by sequestering ORA59 in the cytoplasm. However, it cannot be ruled out that other mechanisms, such as SA-mediated post-translational modifications of the transcriptional regulators involved, may play a role in this phenomenon. Recently, Chen and associates (2009) demonstrated that the transcription factors ETHYLENE-INSENSITIVE3 and ETHYLENE-INSENSITIVE3-LIKE1, which are known to mediate ET signaling, repress the expression of the SA biosynthesis gene SID2 to negatively regulate plant innate immunity in Arabidopsis. Hence, the ET pathway may act at different levels in modulating SA-JA cross-talk.

\section{Defense-related life history \\ influences the plant immune response?}

Our results clearly indicate that the final outcome of the interplay between SA, JA, and ET signaling is dependent on the sequence in which these plant hormones are produced. If the SA pathway is activated prior to or at the same time as the JA pathway, then the SA pathway will suppress the JA response. When the JA pathway is activated first in the absence of ET, then SA can still suppress the JA response. However, when the JA and ET pathways are activated simultaneously, then the JA/ET response becomes insensitive to suppression by SA. These findings provide novel insights into our notion that concentration, timing, and sequence of initiation of the SA, JA, and ET signaling pathways are important for the outcome of the SA-JA signal interaction (Mur et al. 2006; Koornneef et al. 2008). The blend of defense signals produced during a plantattacker interaction varies greatly and is highly dependent on the type of invader encountered (De Vos et al. 2005). Hence, the kinetics of phytohormone biosynthesis and signaling during the interaction of a plant with its attackers could be highly decisive in the final outcome of the defense response to the attacker encountered.

In nature, plants often have to deal with multiple attackers. Ecological studies have shown that the induced defense response of a plant to a specific invader can be influenced by the history of the plant in terms of the type of attackers that the plant has encountered in the past (Poelman et al. 2008). In view of our findings, it is tempting to speculate that, when Arabidopsis is first attacked by a SA-inducing pathogen, the SA pathway will suppress JA responses. This will result in enhanced resistance against pathogens that are sensitive to SAdependent defenses (e.g., biotrophs) but it will also lead to enhanced susceptibility to attackers that are sensitive to JA-de-

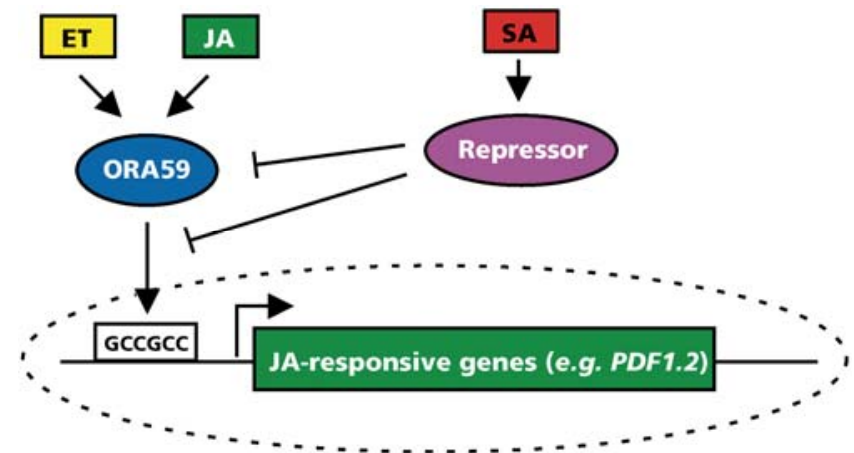

Fig. 8. Model illustrating the interplay between salicylic acid (SA), jasmonic acid (JA), and ethylene (ET) in the SA-mediated downregulation of JA-responsive genes such as PDF1.2. pendent defenses such as necrotrophic pathogens and insects. Vice versa, when a plant is first attacked by a pathogen that strongly activates both the JA and the ET pathways, then these plants develop enhanced resistance to pathogens and insects that are sensitive to JA/ET-dependent defenses. When a secondary SA-inducing pathogen comes into play, the JA/ET-dependent defenses will remain active because they cannot be suppressed by the SA pathway. It must be noted that the data we provide in this article do not necessarily hold true for other plant species. In other plant species, similar molecular mechanisms may operate but the order of signal prioritization may be different among plant species. This may be affected by the ecological context in which a plant species has evolved. A relatively high disease pressure of SA-inducing pathogens may have caused a different signal prioritization compared with a relatively high pressure of JA/ET-inducing pathogens or insect herbivores. The research described in this article provides novel insight into the interplay between SA, JA, and ET signaling and highlights the complexity of the induced defense signaling network that controls the immune response of plants to harmful organisms. Moreover, it provides a basis for future research on the regulation of plant defense responses in a multi-attacker context.

\section{MATERIALS AND METHODS}

\section{Plant material.}

Seed of Arabidopsis thaliana accession Col-0, Col-5, Ler-0, Ws-0, and C24 and the mutant and transgenic genotypes npr 11 (Col-0) (Cao et al. 1994), nprl-2 (Col-0) (Cao et al. 1994), NahG (Col-0) (Delaney et al. 1994), tga2-1/tga3-1/tga51/tga6-1 (Col-0) (Kesarwani et al. 2007), sid2-1 (Col-0) (Nawrath and Métraux 1999), nimin1-1 (Col-0) (Weigel et al. 2005), sec61a (Col-0) (Wang et al. 2005), dadl (Col-0) (Wang et al. 2005), bip2 (Col-0) (Wang et al. 2005), sec6la/bip2 (Col-0) (Wang et al. 2005), dad1/bip2 (Col-0) (Wang et al. 2005), 35S:WRKY70 (Col-0) (Li et al. 2004), wrky70-1 (Col-0) (Li et al. 2006), wrky70-2 (Col-0) (Li et al. 2006), eds1-1 (Ler0) (Falk et al. 1999), dirl (Ws-0) (Maldonado et al. 2002), jarl-1 (Col-0) (Staswick et al. 1992), jin1-2 (Col-0) (Lorenzo et al. 2004), jue2 (Col-0) (Jensen et al. 2002), joe2 (Col-0) (Jensen et al. 2002), cevl (Col-5) (Ellis and Turner 2001), aba2-1 (Col-0) (Koornneef et al. 1982), abil (Ler-0) (Assmann et al. 2000), pad2 (Col-0) (Glazebrook and Ausubel 1994), pad3-1 (Col-0) (Glazebrook and Ausubel 1994), pad4 (Col-0) (Glazebrook and Ausubel 1994), cyp79B2 (Ws-0) (Zhao et al. 2002), cyp79B3 (Ws-0) (Zhao et al. 2002), cyp79B2B3 (Ws-0) (Zhao et al. 2002), ein2-1 (Col-0) (Guzmán and Ecker 1990), ein3-1 (Col-0) (Guzmán and Ecker 1990), etr1-1 (Col-0) (Bleecker et al. 1988), axr1-24 (Col-0) (Tiryaki and Staswick 2002), axr1-12 (Col-0) (Lincoln et al. 1990), axr6-1 (Col-0) (Hellmann et al. 2003), axr6-2 (Col-0) (Hellmann et al. 2003), pidl (Ler-0) (Lee and Cho 2006), tirl-1 (Col-0) (Ruegger et al. 1998), gal-3 (Ler-0), (Koornneef and Van der Veen 1980), DELLA-quadruple (Ler-0) (Cheng et al. 2004), vtc1 (Col-0) (Conklin et al. 1997), cadl-1 (Col-0), (Howden et al. 1995), cad2-1 (Col-0) (Howden et al. 1995), cas1 (C24) (Kubigsteltig and Weiler 2003), ctrl (Col-0) (Kieber et al. 1993), and 35S:ORA59 line 19-2 (Col-0) (Pré et al. 2008) were sown in quartz sand. After 2 weeks, seedlings were transferred to $60-\mathrm{ml}$ pots containing a sand/potting soil mixture that was autoclaved twice for $20 \mathrm{~min}$ (Pieterse et al. 1998). Plants were cultivated in a growth chamber with an 8 -h day $\left(24^{\circ} \mathrm{C}\right)$ and 16 -h night $\left(20^{\circ} \mathrm{C}\right)$ cycle at $70 \%$ relative humidity for another 3 weeks. Plants were watered every other day and received half-strength Hoagland nutrient solution (Hoagland and Arnon 1938) containing $10 \mathrm{mM}$ Sequestreen (CIBA-Geigy) once a week. 


\section{Pathogen bioassays.}

B. cinerea strain B0510 and A. brassicicola strain MUCL 20297 were grown on potato dextrose agar (PDA; Difco Laboratories, Detroit) plates for 2 weeks at $22^{\circ} \mathrm{C}$. Subsequently, conidia were collected as described (Broekaert et al. 1990; Thomma et al. 1998). Plants were inoculated when 5 weeks old by applying 5 - $\mu$ l droplets of half-strength potato dextrose broth containing $5 \times 10^{5}$ spores $/ \mathrm{ml}$, as described previously (Van der Ent et al. 2008).

\section{Chemical treatments.}

Plants were treated with SA, MeJA, or ACC by dipping the leaves into a solution of $0.015 \%$ (vol/vol) Silwet L77 (Van Meeuwen Chemicals BV, Weesp, The Netherlands) containing the indicated concentrations of SA (Mallinckrodt Baker, Deventer, The Netherlands), MeJA (Serva, Brunschwig Chemie, Amsterdam, The Netherlands), or ACC (Sigma, Schnelldorf, Germany) or a combination of these chemicals, as described previously (Spoel et al. 2003; Koornneef et al. 2008). Control treatments were dipped into a solution containing $0.015 \%$ (vol/vol) Silwet L77. MeJA was added to the solutions from a 1,000-fold concentrated stock in $96 \%$ ethanol. To the solutions without MeJA, a similar volume of $96 \%$ ethanol was added.

Application of gaseous ET to the plants was performed as described by Millenaar and associates (2005). In brief, gaseous ET (100 $\mu$ liter $^{-1}$; Hoek Loos, Amsterdam, The Netherlands) and air (70\% relative humidity) were mixed using flow meters (Brooks Instruments, Veenendaal, The Netherlands) to generate an output concentration of ET at $10 \mu$ liter $^{-1}$, which was flushed continuously through glass cuvettes ( 13.5 by 16.0 by $29.0 \mathrm{~cm}$ ) at a flow rate of 75 liters $\mathrm{h}^{-1}$ and then vented to the outside of the building. The concentration of ET in the airflow was verified using gas chromatography as described by Millenaar and associates (2005). Control plants were treated in a similar manner but without ET in the air flow.

\section{Inhibition of ET signaling with 1-MCP.}

To inhibit ET signaling, plants were treated with gaseous 1MCP, which is released from EthylBloc (Floralife, Walterboro, SC, U.S.A.). EthylBloc contains $0.14 \%$ (wt/wt) 1-MCP. To release 1-MCP, EthylBloc was first dissolved in water in an air-tight container at $40^{\circ} \mathrm{C}$ for 12 min (Millenaar et al. 2005). Gaseous 1-MCP was then collected from the headspace with a syringe and injected into an airtight 18-liter cuvette in which the plants were placed for the SA-JA cross-talk assay. For a final concentration of $1-\mathrm{MCP}$ at $1 \mu \mathrm{liter}^{-1}$, EthylBloc was used at $1.6 \mathrm{~g} / \mathrm{m}^{3}$. The pad3-1 mutant plants were pretreated with $1-\mathrm{MCP}$ at $1 \mu \mathrm{l} \operatorname{liter}^{-1}$ for $2 \mathrm{~h}$, after which the cuvettes were opened and plants were inoculated with the fungus $A$. brassicicola as described above. Subsequently, the plants were placed back in air-tight cuvettes for $24 \mathrm{~h}$. Thereafter, plants were treated with $1 \mathrm{mM} \mathrm{SA}$ at 24,48 , and $72 \mathrm{~h}$ postinoculation. Another $24 \mathrm{~h}$ after SA treatment, leaf tissue was harvested for gene expression analysis. During the whole experiment, plants were constantly treated with $1-\mathrm{MCP}$ at $1 \mu$ liter $^{-1}$ to assure inhibition of ET signaling.

\section{ET measurements.}

To measure ET production in plants challenged with $A$. brassicicola, rosettes of inoculated plants were detached from the roots, weighed, and placed individually in 35-ml gas-tight serum flasks $(n=10)$ that were subsequently incubated under climate chamber conditions. At different time intervals, 1-ml gas samples were withdrawn through the rubber seal. The concentration of ET was measured by gas chromatography as described by De Laat and Van Loon (1982).
RNA extraction and Northern blot analysis.

For RNA extraction, at least five plants per treatment were harvested at the time points indicated. RNA isolation and Northern blot analysis was performed as described previously by Van Wees and associates (1999). Northern blots were hybridized with probes for $P R-1, P D F 1.2$, and VSP2 as described (Van Wees et al. 1999). A probe for ORA59 was made by polymerase chain reaction amplification of cDNA of MeJA-treated plants and the gene-specific primers ORA59-FOR 5'-TTCCCCGGA GAACTCTTCTT-3' and ORA59-REV 5'-TCCGGAGAGATT CTTCAACG-3'. To check for equal loading, blots were stripped and hybridized with a probe for $18 S$ ribosomal RNA. The AGI numbers for the genes studied were At2g14610 (PR-1), At5g44420 (PDF1.2), At5g24770 (VSP2), and At1g06160 (ORA59). After hybridization with $\alpha-{ }^{32} \mathrm{P}-\mathrm{dCTP}-$ labeled probes, blots were exposed for autoradiography. Signal intensities of $P D F 1.2$ and VSP2 probes were quantified using a BioRad Molecular Imager FX with Quantity One software (BioRad, Veenendaal, The Netherlands). All gene expression analyses have been repeated at least twice with similar results.

\section{ACKNOWLEDGMENTS}

We thank R. Joosten, H. van Pelt, I. van der Sluis, D. van der Does, and R. Welschen for technical assistance. This research was supported by VICI grant no. 865.04.002 of the Earth and Life Sciences Foundation, which is subsidized by the Netherlands Organization of Scientific Research.

\section{LITERATURE CITED}

Adie, B., Chico, J. M., Rubio-Somoza, I., and Solano, R. 2007. Modulation of plant defenses by ethylene. J. Plant Growth Regul. 26:160-177.

Assmann, S. M., Snyder, J. A., and Lee, Y. R. J. 2000. ABA-deficient (abal) and ABA-insensitive (abi1-1, abi2-1) mutants of Arabidopsis have a wild-type stomatal response to humidity. Plant Cell Environ. 23:387-395.

Beckers, G. J. M., and Spoel, S. H. 2006. Fine-tuning plant defence signalling: Salicylate versus jasmonate. Plant Biol. 8:1-10.

Berrocal-Lobo, M., and Molina, A. 2004. Ethylene response factor 1 mediates Arabidopsis resistance to the soilborne fungus Fusarium oxysporum. Mol. Plant-Microbe Interact. 17:763-770.

Berrocal-Lobo, M., Molina, A., and Solano, R. 2002. Constitutive expression of ETHYLENE-RESPONSE-FACTOR1 in Arabidopsis confers resistance to several necrotrophic fungi. Plant J. 29:23-32.

Bezemer, T. M., and Van Dam, N. M. 2005. Linking aboveground and belowground interactions via induced plant defenses. Trends Ecol. Evol. 20:617-624.

Bleecker, A. B., Estelle, M. A., Sommerville, C., and Kende, H. 1988. Insensitivity to ethylene conferred by a dominant mutation in Arabidopsis thaliana. Science 241:1086-1089.

Bostock, R. M. 1999. Signal conflicts and synergies in induced resistance to multiple attackers. Physiol. Mol. Plant Pathol. 55:99-109.

Bostock, R. M. 2005. Signal crosstalk and induced resistance: Straddling the line between cost and benefit. Annu. Rev. Phytopathol. 43:545-580.

Broekaert, W. F., Terras, F. R. G., Cammue, B. P. A., and Vanderleyden, J. 1990. An automated quantitative assay for fungal growth. FEMS (Fed. Eur. Microbiol. Soc.) Microbiol. Lett. 69:55-60.

Broekaert, W. F., Delaure, S. L., De Bolle, M. F. C., and Cammuel, B. P. A. 2006. The role of ethylene in host-pathogen interactions. Annu. Rev. Phytopathol. 44:393-416.

Cao, H., Bowling, S. A., Gordon, A. S., and Dong, X. 1994. Characterization of an Arabidopsis mutant that is nonresponsive to inducers of systemic acquired resistance. Plant Cell 6:1583-1592.

Chen, H., Xue, L., Chintamanani, S., Germain, H., Lin, H., Cui, H., Cai, R., Zuo, J., Tang, X., Li, X., Guo, H., and Zhou, J. M. 2009. ETHYLENE INSENSITIVE3 and ETHYLENE INSENSITIVE3-LIKE1 repress SALICYLIC ACID INDUCTION DEFICIENT2 expression to negatively regulate plant innate immunity in Arabidopsis. Plant Cell 21:2527-2540.

Cheng, H., Qin, L., Lee, S., Fu, X., Richards, D. E., Cao, D., Luo, D., Harberd, N. P., and Peng, J. 2004. Gibberellin regulates Arabidopsis floral development via suppression of DELLA protein function. Development 131:1055-1064.

Conklin, P. L., Pallanca, J. E., Last, R. L., and Smirnoff, N. 1997. L-ascorbic acid metabolism in the ascorbate-deficient Arabidopsis mutant vtcl. Plant Physiol. 115:1277-1285. 
De Laat, A. M. M., and Van Loon, L. C. 1982. Regulation of ethylene biosynthesis in virus-infected tobacco leaves. II. Time course of levels of intermediates and in vivo conversion rates. Plant Physiol. 69:240-245.

Delaney, T. P., Uknes, S., Vernooij, B., Friedrich, L., Weymann, K., Negrotto, D., Gaffney, T., Gut-Rella, M., Kessmann, H., Ward, E., and Ryals, J. 1994. A central role of salicylic acid in plant disease resistance. Science 266:1247-1250.

Després, C., DeLong, C., Glaze, S., Liu, E., and Fobert, P. R. 2000. The Arabidopsis NPR1/NIM1 protein enhances the DNA binding activity of a subgroup of the TGA family of bZIP transcription factors. Plant Cell $12: 279-290$

De Vos, M., Van Oosten, V. R., Van Poecke, R. M. P., Van Pelt, J. A., Pozo, M. J., Mueller, M. J., Buchala, A. J., Métraux, J. P., Van Loon, L. C., Dicke, M., and Pieterse, C. M. J. 2005. Signal signature and transcriptome changes of Arabidopsis during pathogen and insect attack. Mol. Plant-Microbe Interact. 18:923-937.

De Vos, M., Van Zaanen, W., Koornneef, A., Korzelius, J. P., Dicke, M. Van Loon, L. C., and Pieterse, C. M. J. 2006. Herbivore-induced resistance against microbial pathogens in Arabidopsis. Plant Physiol. 142:352-363

Dong, X. 1998. SA, JA, ethylene, and disease resistance in plants. Curr. Opin. Plant Biol. 1:316-323.

Dong, X. 2004. NPR1, all things considered. Curr. Opin. Plant Biol. 7:547-552.

Ellis, C., and Turner, J. G. 2001. The Arabidopsis mutant cev1 has constitutively active jasmonate and ethylene signal pathways and enhanced resistance to pathogens. Plant Cell 13:1025-1033.

Ellis, C., Karafyllidis, L., and Turner, J. G. 2002a. Constitutive activation of jasmonate signaling in an Arabidopsis mutant correlates with enhanced resistance to Erysiphe cichoracearum, Pseudomonas syringae, and Myzus persicae. Mol. Plant-Microbe Interact. 15:1025-1030.

Ellis, C., Karafyllidis, I., Wasternack, C., and Turner, J. G. 2002b. The Arabidopsis mutant cev1 links cell wall signaling to jasmonate and ethylene responses. Plant Cell 14:1557-1566.

Falk, A., Feys, B. J., Frost, L. N., Jones, J. D. G., Daniels, M. J., and Parker, J. E. 1999. EDS1, an essential component of $R$ gene-mediated disease resistance in Arabidopsis has homology to eukaryotic lipases. Proc. Natl. Acad. Sci. U.S.A. 96:3292-3297.

Felton, G. W., and Korth, K. L. 2000. Trade-offs between pathogen and herbivore resistance. Curr. Opin. Plant Biol. 3:309-314.

Glazebrook, J. 2005. Contrasting mechanisms of defense against biotrophic and necrotrophic pathogens. Annu. Rev. Phytopathol. 43:205-227.

Glazebrook, J., and Ausubel, F. M. 1994. Isolation of phytoalexin-deficient mutants of Arabidopsis thaliana and characterization of their interactions with bacterial pathogens. Proc. Natl. Acad. Sci. U.S.A. 91:89558959.

Glazebrook, J., Chen, W., Estes, B., Chang, H.-S., Nawrath, C., Métraux, J.-P., Zhu, T., and Katagiri, F. 2003. Topology of the network integrating salicylate and jasmonate signal transduction derived from global expression phenotyping. Plant J. 34:217-228.

Grant, M., and Lamb, C. 2006. Systemic immunity. Curr. Opin. Plant Biol 9:414-420.

Guzmán, P., and Ecker, J. R. 1990. Exploiting the triple response of Arabidopsis to identify ethylene-related mutants. Plant Cell 2:513-523.

Hellmann, H., Hobbie, L., Chapman, A., Dharmasiri, S., Dharmasiri, N., del Pozo, C., Reinhardt, D., and Estelle, M. 2003. Arabidopsis AXR6 encodes CUL1 implicating SCF E3 ligases in auxin regulation of embryogenesis. EMBO (Eur. Mol. Biol. Organ.) J. 22:3314-3325.

Hoagland, D. R., and Arnon, D. I. 1938. The water culture method for growing plants without soil. Calif. Agric. Exp. Stn. Bull. 347:36-39.

Howden, R., Andersen, C. R., Goldsbrough, P. B., and Cobbett, C. S. 1995. A cadmium-sensitive, glutathione-deficient mutant of Arabidopsis thaliana. Plant Physiol. 107:1067-1073.

Howe, G. A., and Jander, G. 2008. Plant immunity to insect herbivores Annu. Rev. Plant Biol. 59:41-66.

Jensen, A. B., Raventos, D., and Mundy, J. 2002. Fusion genetic analysis of jasmonate-signalling mutants in Arabidopsis. Plant J. 29:595-606.

Kazan, K., and Manners, J. M. 2008. Jasmonate signaling: Toward an integrated view. Plant Physiol. 146:1459-1468.

Kesarwani, M., Yoo, J., and Dong, X. 2007. Genetic interactions of TGA transcription factors in the regulation of pathogenesis-related genes and disease resistance in Arabidopsis. Plant Physiol. 144:336-346.

Kessler, A., and Baldwin, I. T. 2002. Plant responses to insect herbivory: The emerging molecular analysis. Annu. Rev. Plant Biol. 53:299-328.

Kieber, J. J., Rothenberg, M., Roman, G., Feldmann, K. A., and Ecker, J. R. 1993. CTR1, a negative regulator of the ethylene response pathway in Arabidopsis, encodes a member of the Raf family of protein kinases. Cell 72:427-441.

Koornneef, A., and Pieterse, C. M. J. 2008. Cross-talk in defense signaling. Plant Physiol. 146:839-844.
Koornneef, A., Leon-Reyes, A., Ritsema, T., Verhage, A., Den Otter, F. C., Van Loon, L. C., and Pieterse, C. M. J. 2008. Kinetics of salicylate-mediated suppression of jasmonate signaling reveal a role for redox modulation. Plant Physiol. 147:1358-1368.

Koornneef, M., and Van der Veen, J. H. 1980. Induction and analysis of gibberellin-sensitive mutants in Arabidopsis thaliana (L.) Heynh. Theor. Appl. Genet. 58:257-263.

Koornneef, M., Jorna, M. L., Brinkhorst-Van der Swan, D. L. C., and Karssen, C. M. 1982. The isolation of abscissic acid (ABA)-deficient mutants by selection of induced revertants in non-germinating gibberellin sensitive lines of Arabidopsis thaliana (L.) Heynh. Theor. Appl Genet. 61:385-393

Kubigsteltig, I. I., and Weiler, E. W. 2003. Arabidopsis mutants affected in the transcriptional control of allene oxide synthase, the enzyme catalyzing the entrance step in octadecanoid biosynthesis. Planta 217:748-757.

Kunkel, B. N., and Brooks, D. M. 2002. Cross talk between signaling pathways in pathogen defense. Curr. Opin. Plant Biol. 5:325-331.

Lee, S. H., and Cho, H. T. 2006. PINOID positively regulates auxin efflux in Arabidopsis root hair cells and tobacco cells. Plant Cell 18:16041616.

Leon-Reyes, A., Spoel, S. H., De Lange, E. S., Abe, H., Kobayashi, M., Tsuda, S., Millenaar, F. F., Welschen, R. A. M., Ritsema, T., and Pieterse, C. M. J. 2009. Ethylene modulates the role of NONEXPRESSOR OF PATHOGENESIS-RELATED GENES1 in cross talk between salicylate and jasmonate signaling. Plant Physiol. 149:1797-1809.

Li, J., Brader, G., and Palva, E. T. 2004. The WRKY70 transcription factor: A node of convergence for jasmonate-mediated and salicylate-mediated signals in plant defense. Plant Cell 16:319-331.

Li, J., Brader, G., Kariola, T., and Palva, E. T. 2006. WRKY70 modulates the selection of signaling pathways in plant defense. Plant J. 46:477491.

Lincoln, C., Britton, J. H., and Estelle, M. 1990. Growth and development of the axr1 mutants of Arabidopsis. Plant Cell 2:1071-1080.

Loake, G., and Grant, M. 2007. Salicylic acid in plant defence-the players and protagonists. Curr. Opin. Plant Biol. 10:466-472.

Lorenzo, O., and Solano, R. 2005. Molecular players regulating the jasmonate signalling network. Curr. Opin. Plant Biol. 8:532-540.

Lorenzo, O., Piqueras, R., Sánchez-Serrano, J. J., and Solano, R. 2003. ETHYLENE RESPONSE FACTOR1 integrates signals from ethylene and jasmonate pathways in plant defense. Plant Cell 15:165-178.

Lorenzo, O., Chico, J. M., Sanchez-Serrano, J. J., and Solano, R. 2004. JASMONATE-INSENSITIVE1 encodes a MYC transcription factor essential to discriminate between different jasmonate-regulated defense responses in Arabidopsis. Plant Cell 16:1938-1950.

Maldonado, A. M., Doerner, P., Dixon, R. A., Lamb, C. J., and Cameron, R. K. 2002. A putative lipid transfer protein involved in systemic resistance signalling in Arabidopsis. Nature 419:399-403.

Millenaar, F. F., Cox, M. C. H., de Jong van Berkel, Y. E. M., Welschen, R. A. M., Pierik, R., Voesenek, L. A. C. J., and Peeters, A. J. M. 2005. Ethylene-induced differential growth of petioles in Arabidopsis. Analyzing natural variation, response kinetics, and regulation. Plant Physiol. 137:998-1008.

Mur, L. A. J., Kenton, P., Atzorn, R., Miersch, O., and Wasternack, C. 2006. The outcomes of concentration-specific interactions between salicylate and jasmonate signaling include synergy, antagonism, and oxidative stress leading to cell death. Plant Physiol. 140:249-262.

Nawrath, C., and Métraux, J.-P. 1999. Salicylic acid induction-deficient mutants of Arabidopsis express $P R-2$ and $P R-5$ and accumulate high levels of camalexin after pathogen inoculation. Plant Cell 11:1393 1404

Ndamukong, I., Abdallat, A. A., Thurow, C., Fode, B., Zander, M., Weigel, R., and Gatz, C. 2007. SA-inducible Arabidopsis glutaredoxin interacts with TGA factors and suppresses JA-responsive PDF1.2 transcription. Plant J. 50:128-139.

Penninckx, I. A. M. A., Thomma, B. P. H. J., Buchala, A., Métraux, J.-P and Broekaert, W. F. 1998. Concomitant activation of jasmonate and ethylene response pathways is required for induction of a plant defensin gene in Arabidopsis. Plant Cell 10:2103-2113.

Pieterse, C. M. J., and Dicke, M. 2007. Plant interactions with microbes and insects: From molecular mechanisms to ecology. Trends Plant Sci. 12:564-569.

Pieterse, C. M. J., Van Wees, S. C. M., Van Pelt, J. A., Knoester, M., Laan, R., Gerrits, H., Weisbeek, P. J., and Van Loon, L. C. 1998. A novel signaling pathway controlling induced systemic resistance in Arabidopsis. Plant Cell 10:1571-1580.

Pieterse, C. M. J., Leon-Reyes, A., Van der Ent, S., and Van Wees, S. C. M. 2009. Networking by small-molecules hormones in plant immunity. Nature Chem. Biol. 5:308-316.

Poelman, E. H., Broekgaarden, C., Van Loon, J. J. A., and Dicke, M. 2008. Early season herbivore differentially affects plant defence responses to 
subsequently colonizing herbivores and their abundance in the field Mol. Ecol. 17:3352-3365.

Pré, M., Atallah, M., Champion, A., De Vos, M., Pieterse, C. M. J., and Memelink, J. 2008. The AP2/ERF domain transcription factor ORA59 integrates jasmonic acid and ethylene signals in plant defense. Plant Physiol. 147:1347-1357.

Reymond, P., and Farmer, E. E. 1998. Jasmonate and salicylate as global signals for defense gene expression. Curr. Opin. Plant Biol. 1:404-411.

Robert-Seilaniantz, A., Navarro, L., Bari, R., and Jones, J. D. G. 2007. Pathological hormone imbalances. Curr. Opin. Plant Biol. 10:372379

Ruegger, M., Dewey, E., Gray, W. M., Hobbie, L., Turner, J., and Estelle, M. 1998. The TIR1 protein of Arabidopsis functions in auxin response and is related to human SKP2 and yeast Grr1p. Genes Dev. 12:198-207.

Schenk, P. M., Kazan, K., Wilson, I., Anderson, J. P., Richmond, T., Somerville, S. C., and Manners, J. M. 2000. Coordinated plant defense responses in Arabidopsis revealed by microarray analysis. Proc. Natl. Acad. Sci. U.S.A. 97:11655-11660.

Spoel, S. H., and Dong, X. 2008. Making sense of hormone crosstalk during plant immune responses. Cell Host Microbe 3:348-351.

Spoel, S. H., Koornneef, A., Claessens, S. M. C., Korzelius, J. P., Van Pelt, J. A., Mueller, M. J., Buchala, A. J., Métraux, J.-P., Brown, R., Kazan, K., Van Loon, L. C., Dong, X., and Pieterse, C. M. J. 2003. NPR1 modulates cross-talk between salicylate- and jasmonate-dependent defense pathways through a novel function in the cytosol. Plant Cell 15:760-770

Spoel, S. H., Johnson, J. S., and Dong, X. 2007. Regulation of tradeoffs between plant defenses against pathogens with different lifestyles. Proc. Natl. Acad. Sci. U.S.A. 104:18842-18847.

Staswick, P. E., Yuen, G. Y., and Lehman, C. C. 1992. Methyl jasmonate inhibition of root growth and induction of a leaf protein are decreased in an Arabidopsis thaliana mutant. Proc. Natl. Acad. Sci. U.S.A. 89:6837-6840.

Stout, M. J., Thaler, J. S., and Thomma, B. P. H. J. 2006. Plant-mediated interactions between pathogenic microorganisms and herbivorous arthropods. Annu. Rev. Entomol. 51:663-689.

Thaler, J. S., Karban, R., Ullman, D. E., Boege, K., and Bostock, R. M. 2002. Cross-talk between jasmonate and salicylate plant defense pathways: Effects on several plant parasites. Oecologia 131:227-235.

Thomma, B. P. H. J., Eggermont, K., Penninckx, I. A. M. A., Mauch-Mani, B., Vogelsang, R., Cammue, B. P. A., and Broekaert, W. F. 1998. Separate jasmonate-dependent and salicylate-dependent defense-response pathways in Arabidopsis are essential for resistance to distinct microbial pathogens. Proc. Natl. Acad. Sci. U.S.A. 95:15107-15111.

Thomma, B. P. H. J., Nelissen, I., Eggermont, K., and Broekaert, W. F. 1999. Deficiency in phytoalexin production causes enhanced susceptibility of Arabidopsis thaliana to the fungus Alternaria brassicicola. Plant J. 19:163-171.

Thomma, B. P. H. J., Eggermont, K., Broekaert, W. F., and Cammue, B. P. A. 2000. Disease development of several fungi on Arabidopsis can be reduced by treatment with methyl jasmonate. Plant Physiol. Biochem. 38:421-427.

Thomma, B. P. H. J., Tierens, K. F. M., Penninckx, I. A. M. A., MauchMani, B., Broekaert, W. F., and Cammue, B. P. A. 2001. Different micro-organisms differentially induce Arabidopsis disease response path- ways. Plant Physiol. Biochem. 39:673-680.

Tiryaki, I., and Staswick, P. E. 2002. An Arabidopsis mutant defective in jasmonate response is allelic to the auxin-signaling mutant axr1. Plant Physiol. 130:887-894.

Van der Ent, S., Verhagen, B. W. M., Van Doorn, R., Bakker, D., Verlaan, M. G., Pel, M. J. C., Joosten, R. G., Proveniers, M. C. G., Van Loon, L. C., Ton, J., and Pieterse, C. M. J. 2008. MYB72 is required in early signaling steps of rhizobacteria-induced systemic resistance in Arabidopsis. Plant Physiol. 146:1293-1304.

Van der Ent, S., Van Wees, S. C. M., and Pieterse, C. M. J. 2009. Jasmonate signals in plant interactions with beneficial microbes. Phytochemistry 70:1581-1588.

Van der Putten, W. H., Vet, L. E. M., Harvey, J. A., and Wäckers, F. L. 2001. Linking above- and belowground multitrophic interactions of plants, herbivores, pathogens, and their antagonists. Trends Ecol. Evol. 16:547-554.

Van Loon, L. C., Geraats, B. P. J., and Linthorst, H. J. M. 2006. Ethylene as a modulator of disease resistance in plants. Trends Plant Sci. 11:184191.

Van Wees, S. C. M., Luijendijk, M., Smoorenburg, I., Van Loon, L. C., and Pieterse, C. M. J. 1999. Rhizobacteria-mediated induced systemic resistance (ISR) in Arabidopsis is not associated with a direct effect on expression of known defense-related genes but stimulates the expression of the jasmonate-inducible gene Atvsp upon challenge. Plant Mol. Biol. 41:537-549.

Van Wees, S. C. M., De Swart, E. A. M., Van Pelt, J. A., Van Loon, L. C., and Pieterse, C. M. J. 2000. Enhancement of induced disease resistance by simultaneous activation of salicylate- and jasmonate-dependent defense pathways in Arabidopsis thaliana. Proc. Natl. Acad. Sci. U.S.A. 97:8711-8716.

Van Wees, S. C. M., Van der Ent, S., and Pieterse, C. M. J. 2008. Plant immune responses triggered by beneficial microbes. Curr. Opin. Plant Biol. 11:443-448.

Vlot, A. C., Klessig, D. F., and Park, S.-W. 2008. Systemic acquired resistance: The elusive signal(s). Curr. Opin. Plant Biol. 11:436-442.

Von Dahl, C. C., and Baldwin, I. T. 2007. Deciphering the role of ethylene in plant-herbivore interactions. J. Plant Growth Regul. 26:201-209.

Walling, L. L. 2008. Avoiding effective defenses: Strategies employed by phloem-feeding insects. Plant Physiol. 146:859-866.

Walters, D., and Heil, M. 2007. Costs and trade-offs associated with induced resistance. Physiol. Mol. Plant Pathol. 71:3-17.

Walters, D., Newton, A., and Lyon, G. 2007. Induced Resistance for Plant Defence: A Sustainable Approach to Crop Protection. Blackwell, Oxford.

Wang, D., Weaver, N. D., Kesarwani, M., and Dong, X. 2005. Induction of protein secretory pathway is required for systemic acquired resistance. Science 308:1036-1040.

Weigel, R. R., Pfitzner, U. M., and Gatz, C. 2005. Interaction of NIMIN1 with NPR1 modulates $P R$ gene expression in Arabidopsis. Plant Cell 17:1279-1291.

Zarei, A. 2007. Functional analysis of jasmonate-responsive transcription factors in Arabidopsis thaliana. Ph.D. thesis, Leiden University. The Netherlands

Zhao, Y., Hull, A. K., Gupta, N. R., Goss, K. A., Alonso, J., Ecker, J. R., Normanly, J., Chory, J., and Celenza, J. L. 2002. Trp-dependent auxin biosynthesis in Arabidopsis: Involvement of cytochrome P450s CYP79B2 and CYP79B3. Genes Dev. 16:3100-3112. 